\title{
Special issue of the Czech Society for Operations Research
}

\author{
Josef Jablonsky • Petr Fiala
}

Published online: 14 March 2012

(C) Springer-Verlag 2012

This special issue contains selected papers of the 28th International Conference Mathematical Methods in Economics (MME) that took place in the city of Ceske Budejovice in September 2010. It is a traditional annual meeting of professionals from universities and business who are interested in the theory and applications of operations research and econometrics organized by the Czech Society for Operations Research (CSOR) together with the Czech Econometric Society in various places within the Czech Republic. The number of participants is rapidly increasing in the last years. Usually between 100 and 200 professionals are presenting their research results every year. Although the conference is the annual meeting of the CSOR there are always participants from all around the world especially from surrounding countries as Slovakia, Poland, Austria, Germany, Slovenia, etc. Accepted papers presented at the conference are published in the Book of Proceedings that is indexed in CPCI (Conference Proceedings Citation Index) since 2003.

Main organizer of the Conference MME is the CSOR. It is a quite small professional society with approx. 50 regular members but its activities are numerous. Except the mentioned international conference Mathematical Methods in Economics the main international activity was organization of the 22nd European Conference on Operational Research EURO XXII in 2007. This conference was organized by the CSOR in cooperation with the University of Economics, Prague. EURO XXII was a very successful event, by attending of more than two thousands of participants from all over the world it was one of the largest EURO conferences at all.

The conferences MME cover both theoretical and application aspects of mathematical modeling of economic processes. The scope of the conference involves operations

\footnotetext{
J. Jablonsky $(\varangle) \cdot$ P. Fiala

Faculty of Informatics and Statistics, University of Economics Prague,

W. Churchill Sq. 4, 13067 Praha 3, Czech Republic

e-mail: jablon@vse.cz
} 
research, econometrics, mathematical economics and other related areas. The special issue contains a selection of accepted papers of various operations research fields. All of them were presented during the conference and then submitted to the CEJOR special issue. The manuscripts were reviewed by two or three anonymous reviewers and finally 9 papers were accepted for publication. The accepted papers cover various operations research fields: project management, data envelopment analysis, financial optimization, revenue management, vehicle routing, crop planning optimization, stochastic optimization, and duality in separable problems. Bartoska and Subrt (2012) deal with the effect of a human agent on the activity realization in a project. Fiala (2012) proposes a framework for solving network revenue management problems with customer choice behavior based on three inter-related network structures. Friebel and Friebelova (2012) suggest a model of optimal replacement of the most critical computer component that minimizes repair costs during the warranty period. A general duality theory of max-separable optimization problems is proposed by Gavalec and Zimmermann (2012). The paper (Hajek 2012) presents an analysis of credit rating by using feature selection methods and fuzzy rule-based systems. Jablonsky (2012) formulates two original procedures for ranking of efficient units in data envelopment analysis models that are based on multiple criteria decision making techniques-goal programming and analytic hierarchy process. Janova (2012) develops a validation and verification procedures for crop planning optimization models in agriculture when the randomness of harvests is considered and complex crop rotation restrictions must hold. Pelikan and Fabry (2012) deal with formulation and solving of pickup and delivery problem with split demand and reloading. The paper (Vaclavik and Jablonsky 2012) focuses on portfolio optimization. An extension and re-formulation of standard Markowitz optimization model is discussed.

\section{References}

Bartoska J, Subrt T (2012) The effect of human agent in project management. Cent Eur J Oper Res 20(3). doi:10.1007/s10100-011-0209-4

Fiala P (2012) A framework for solving network revenue management problems with customer choice behavior. Cent Eur J Oper Res 20(3). doi:10.1007/s10100-012-0241-Z

Friebel L, Friebelova J (2012) Stochastic analysis of maintenance process costs in the IT industry: a case study. Cent Eur J Oper Res 20(3). doi:10.1007/s10100-011-0213-8

Gavalec M, Zimmermann K (2012) Duality for max-separable problems. Cent Eur J Oper Res 20(3). doi:10. 1007/s10100-011-0203-X

Hájek P (2012) Credit rating analysis using adaptive fuzzy rule-based systems: an industry-specific approach. Cent Eur J Oper Res 20(3). doi:10.1007/s10100-011-0229-0

Jablonsky J (2012) Multicriteria approaches for ranking of efficient units in DEA models. Cent Eur J Oper Res 20(3). doi:10.1007/s10100-011-0223-6

Janová J (2012) Crop planning optimization model: the validation and verification processes. Cent Eur J Oper Res 20(3). doi:10.1007/s10100-011-0205-8

Pelikán J, Fábry J (2012) Heuristics for routes generation in pickup and delivery problem. Cent Eur J Oper Res 20(3). doi:10.1007/s10100-012-0239-6

Vaclavik M, Jablonsky J (2012) Revisions of modern portfolio theory optimization model. Cent Eur J Oper Res 20(3). doi:10.1007/s10100-011-0227-2 